\title{
AN ACCURACY PROBLEM OF THE FWD TIME HISTORY WITH REGARD TO THE APPLICATION OF THE SASW METHOD
}

\author{
Jozef KOMAČKA ${ }^{1, *}$
}

${ }^{1}$ Department of Highway Engineering, Faculty of Civil Engineering, University of Žilina, Univerzitná 8215/1, 01026 Žilina, Slovakia.

corresponding author: jozef.komacka@fstav.uniza.sk.

\section{Abstract}

A Falling Weight Deflectometer (FWD) represents one group of the devices used for diagnostics of pavement bearing capacity. Usually, the FWD dynamic load is substituted by a static load in the evaluation process to determine the equivalent modulus of a pavement structure or modulus of pavement layers. However, the data recorded during a bearing capacity test by FWD can be used to reveal the propagation of a dynamic impulse generated by FWD. It gives a possibility to use them in an evaluation method based on the propagation of waves generated by dynamic impulse. Therefore, the FWD time history data was assessed with regard to possible using in the method of the Spectral Analysis of Surface Waves. Basically, the possibility to determine the velocity of a generated surface wave was evaluated. It was found out the same deflection values exist at consecutive time intervals in the relevant part of the time history data (the arrival of the front of the wave or the area of maximum deflection value). Two methods were used to determine the exact time of the wave occurrence at receivers. It was concluded the differences between the used methods exist. It means the calculated velocities of a wave and shear modulus are also different.

Importance of the shear modulus differences were estimated using the Slovak bearing capacity classification based on elastic modulus values. Taking into account the range of modulus in one classification class it can be stated the differences in the shear modulus determined according to used two methods could be very significant if the values calculated for short distance of the receiver are used. In the case of longer distance of the receivers the differences are not so high and significant.
\end{abstract}

\section{Keywords:}

Time;

Wave;

Deflectometer;

Receiver;

Modulus.

\section{Introduction}

Asphalt pavements should be resistant to traffic and climatic conditions during their service life. The level of pavement serviceability and bearing capacity is verified using various diagnostic equipment. A Falling Weight Deflectometer (FWD) represents one group of the devices used for diagnostics of pavement bearing capacity. The change of load force and pavement response over time is registered during the test at an investigation point and saved into a separate time history file. Various types of receivers are used to register the pavement response but finally, this response is transferred into the change of pavement surface deflection over time. Common practice is to use only the maximum value of a pavement surface deflection to evaluate bearing capacity of a pavement. Usually, two main approaches are applied in the evaluation process. The first uses only the maximum deflection at the centreline of a load and the equivalent modulus of a pavement structure is calculated based on the theory of linear elastic half-space. Other way is to use all maximum deflections determined at the distances corresponding to spacing of FWD receivers. Then, the modulus of pavement layers and subgrade can be calculated using the theory of multi-layered linear elastic halfspace. The simplification in both approaches is the FWD dynamic load is substituted by a static load. The propagation of a dynamic impulse generated during a diagnostics test by FWD is essentially in accordance with the basic principle of the method of the Spectral Analysis of Surface Waves (SASW) 
[1], [2]. Therefore, it was investigated if the FWD time history contains all necessary data to apply the SASW method, i.e. if it is possible to determine the velocity of a generated surface wave (Rayleigh's wave).

\section{Basic inputs from the FWD time history to the SASW method}

A Falling Weight Deflectometer (FWD) time history consists of a load force and deflections values in the time scale. As can be seen in Fig. 1, the values of load force and deflections $d$ in various spacing from centreline of load (from $0 \mathrm{~mm}$ to $1500 \mathrm{~mm}$ ) change over time. They increase from initial values to maximum and decrease to final values. Basically, the time history is an overview of a load course and the response of a pavement to the load.

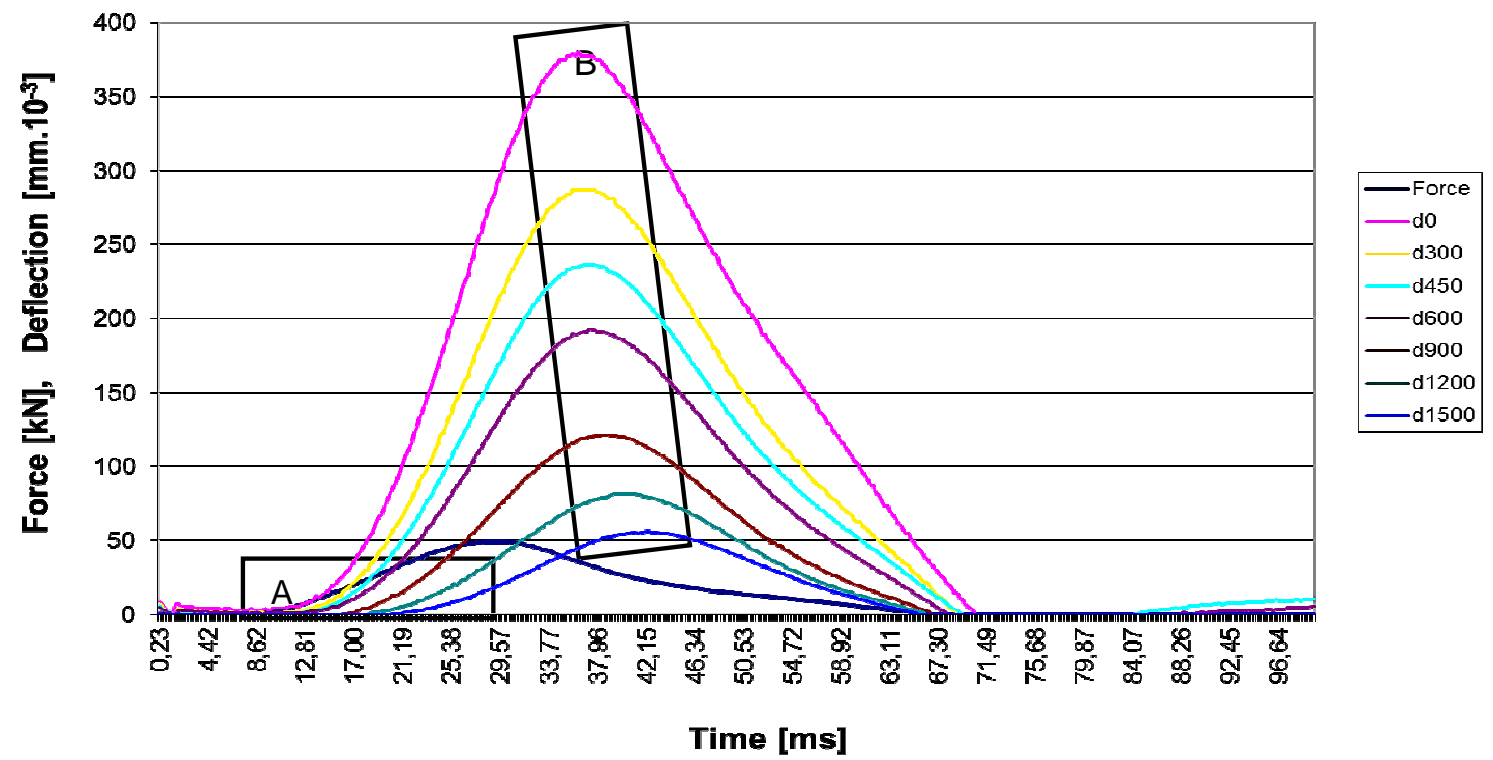

Fig. 1: An example of FWD time history.

The application of the Spectral Analysis of Surface Waves (SASW) method is based on the determination of the Rayleigh`s wave velocity $c_{R}$ from the formula:

$c_{R}=L / t$,

where:

$L$ - the distance of the receivers used for determination of a wave velocity,

$t$ - travel time of a wave between the receivers.

When a FWD load impulse is used to generate Rayleigh's wave the distance of the FWD receivers from the centreline of the load is known. It is only necessary to determine the travel time of Rayleigh's wave between the receivers from the FWD time history. Therefore, the exact time of the Rayleigh`s wave occurrence at individual receivers has to be known. It can be determined using the arrival of the front of the wave to a receiver (the area "A" in Fig. 1) or the maximum value of a surface deflection (the area "B" in Fig. 1). The first approach is based on the fact that an initial value of deflection starts to increase when the wave is arriving to a receiver.

\section{Accuracy problem of the FWD time history}

The numerous FWD time history files were checked. Mostly, they were the outputs of two KUAB FWD devices but a part of the time history files represented the outputs of a Dynatest FWD. Regardless the FWD type the findings were the same. There were a few the same deflection values at consecutive time intervals in the relevant part of the time history data. These findings are valid for all receivers, regardless their distance from the centreline of a load. An example is in Fig 2 . There is a 
part of the FWD Dynatest time history representing the output of asphalt pavement diagnostics. The areas of the front of a wave and the maximum deflection are yellow highlighted. There are the small changes of the deflection values in both time areas of the time history and probably due to the sensitivity and accuracy of the receivers the same values were registered more times.

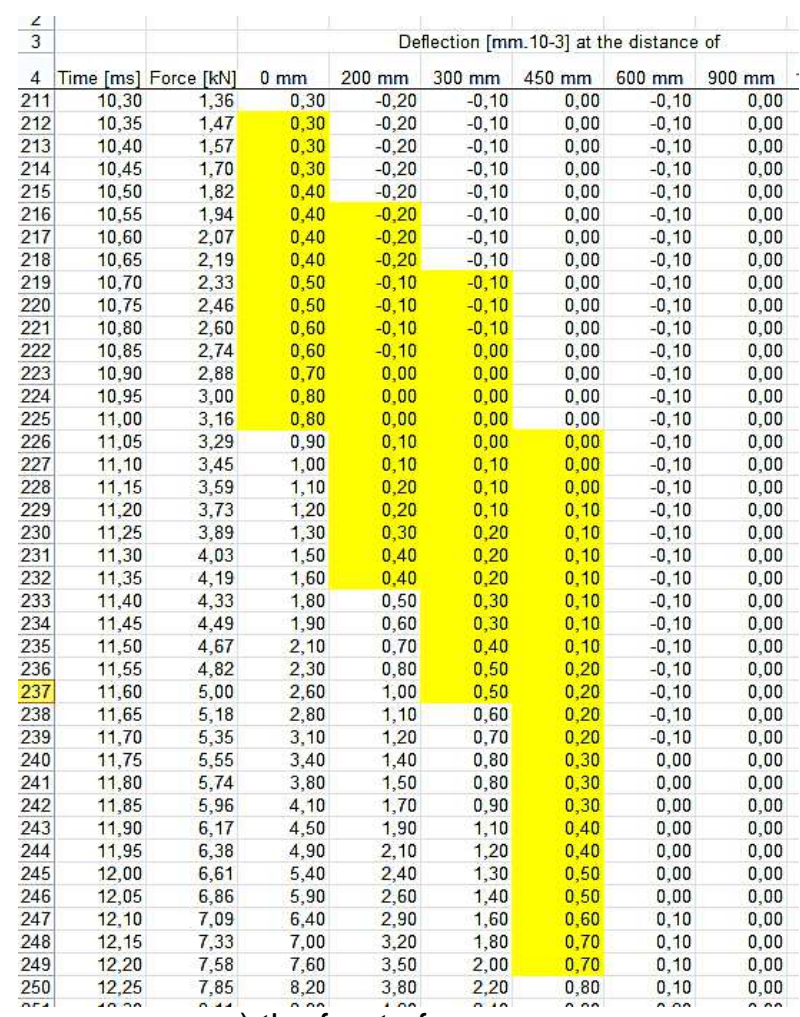

a) the front of a wave

\begin{tabular}{|c|c|c|c|c|c|c|c|c|}
\hline 3 & & & & & ction & $n$-10-3 & dist & \\
\hline 4 & $\mathrm{Tit}_{1}$ & $F$ & $0 \mathrm{~m}$ & 200 & $300 \mathrm{~m}$ & $450 \mathrm{n}$ & $600 \mathrm{~m}$ & $900 \mathrm{r}$ \\
\hline 499 & 24,70 & 40,79 & 579,40 & 457,00 & 384,50 & 298,40 & 233,40 & 130,30 \\
\hline bo & 24,75 & 40,57 & 579,50 & 457,20 & 384,80 & 298,80 & 233,90 & 130,80 \\
\hline 11 & 24,80 & 40,38 & 579,50 & 457,40 & 385,10 & 299,20 & 234,30 & 131,30 \\
\hline 22 & 24,85 & 40,17 & 579,50 & 457,60 & 385,40 & 299,60 & 234,80 & 131,80 \\
\hline 03 & 24,90 & 39,96 & 579,40 & 457,70 & 385,60 & 300,00 & 235,20 & 132,30 \\
\hline 04 & 24,95 & 39,76 & 579,40 & 457,90 & 385,90 & 300,30 & 235,70 & 132,80 \\
\hline 05 & 25,00 & 55 & 579,30 & 458,00 & 386,10 & 0,70 & 236,10 & 133,30 \\
\hline 56 & 25,05 & 34 & 579,20 & & & 00 & 5,50 & 133,80 \\
\hline 7 & 25,10 & 14 & 579,10 & 458,10 & 386,40 & 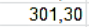 & 236,90 & 134,30 \\
\hline 88 & 25,15 & 93 & 579,00 & 458,20 & 6,60 & 1,60 & 237,30 & 134,80 \\
\hline 09 & & & 80 & & & & & 5,20 \\
\hline 10 & & & 5 & & & & & \\
\hline 11 & 30 & & 578,50 & 20 & & 30 & 30 & 36,10 \\
\hline & & & & & & & & 136,60 \\
\hline (5) & & & 578,00 & 10 & & & & 00 \\
\hline 14 & & & 577,70 & & & & & 7,50 \\
\hline 515 & & & 577,40 & 90 & 20 & 0 & 60 & 137,90 \\
\hline 16 & & & 577 & 30 & & & & 30 \\
\hline 17 & & & & & & & & 70 \\
\hline 18 & 25 & & 576 & 50 & 20 & 0 & & 139,10 \\
\hline 519 & & & 57 & & & & & 50 \\
\hline & & & 5 & & & & & \\
\hline 21 & & & 574 & & & & & 140,30 \\
\hline 22 & & & & & & & & \\
\hline 3 & & & 57 & & & & 24 & 1,00 \\
\hline 524 & & & & & & & & 141,40 \\
\hline 525 & & & & & & & & \\
\hline 26 & & & 572 & & & 0 & 90 & 42,10 \\
\hline 527 & & & & & & & & \\
\hline 528 & & & 57 & & & & & \\
\hline 29 & & & & & & & & 13,00 \\
\hline 2 & & & & & & & & 30 \\
\hline & & & & & & & & \\
\hline 53 & & & & & & & & \\
\hline 533 & & & 56 & & & & 242,50 & 44,20 \\
\hline 53 & & & & & & & & 14. \\
\hline 53 & & & & & & & & 70 \\
\hline 536 & & & $x$ & & & & & \\
\hline & & & & & & & & 145 \\
\hline 538 & 26,65 & & 563,20 & 449,90 & 38 & 90 & 242,60 & \\
\hline 5 & 2670 & 3220 & $56>40$ & 19.30 & 387.30 & 30270 & 24260 & 745 \\
\hline
\end{tabular}

b) the maximum deflection

Fig. 2: Deflection data.

It can be seen in Fig. 2 the change of the deflection with the arrival of the front of the wave is very slow and it is not easy to exactly determine the time span corresponding to the arrival of the wave. Contrary to this, the time span of the maximum deflection can be easy identified in the time history. It seems more suitable to use maximum deflection values for determination of the exact time of the Rayleigh`s wave occurrence at a receiver. The number of the same values in the time span of the maximum deflection can be different at individual receivers. The most simply approach to determine the moment of a wave occurrence at a receiver $\left(t_{w}\right)$ is based on the assumption that it in the middle of the time span with the same values of the maximum deflection. It can be determined as:

$t_{w}=\left(t_{1}+t_{2}\right) / 2$,

where:

$t_{1}$ - time of the first value of maximum deflection,

$t_{2}$ - time of last value of maximum deflection.

This approach does not take into account the course of the deflection change before and after the time span with the maximum values. Thus, other possibility to determine the moment of a wave occurrence at a receiver is using the regression analysis, to determine the equation of the deflection curve in time scale and to calculate time when the maximum is reached. There are the results of calculations for both approaches in Table 1 based on the FWD Dynatest time history. Data in Table 1 confirms the variability of the time span of maximum deflection values. There is the narrow time span only with two values (the receiver at the distance of $1500 \mathrm{~mm}$ ) and also the relatively large time span (the receiver at the distance of $1800 \mathrm{~mm}$ ). The calculated time of the Rayleigh's wave occurrence at the same receiver is mostly not the same for both used approaches. The differences vary from 
negative to positive values. It means there is not the same tendency in time of a wave occurrence at receivers between the used approaches.

Table 1: The results of the calculation of a wave occurrence at a receiver.

\begin{tabular}{|l|c|c|c|c|c|c|c|c|c|}
\hline & \multicolumn{7}{|c|}{ Distance of a receiver from the centreline of a load [mm] } \\
\cline { 2 - 10 } & $\mathbf{0}$ & $\mathbf{2 0 0}$ & $\mathbf{3 0 0}$ & $\mathbf{4 5 0}$ & $\mathbf{6 0 0}$ & $\mathbf{9 0 0}$ & $\mathbf{1 2 0 0}$ & $\mathbf{1 5 0 0}$ & $\mathbf{1 8 0 0}$ \\
\hline $\begin{array}{l}\text { Time span of the deflection } \\
\text { maximum [m-s] }\end{array}$ & 0.20 & 0.30 & 0.20 & 0.35 & 0.10 & 0.20 & 0.20 & 0.05 & 0.40 \\
\hline $\begin{array}{l}t_{w} \text { according to the formula (2) } \\
{[\mathrm{m} \cdot \mathrm{s}]}\end{array}$ & 24.35 & 24.65 & 24.90 & 25.28 & 25.80 & 27.05 & 28.75 & 30.78 & 32.80 \\
\hline $\begin{array}{l}t_{w} \text { from the equation of } \\
\text { deflection curve [m·s] }\end{array}$ & 24.25 & 24.58 & 24.84 & 25.25 & 25.77 & 27.17 & 28.75 & 30.79 & 32.86 \\
\hline Time difference [m.s] & -0.10 & -0.07 & -0.06 & -0.03 & -0.03 & 0.12 & 0.00 & 0.01 & 0.06 \\
\hline
\end{tabular}

The different time of a wave occurrence at receivers determined according to two procedures leads to a difference in the velocity of the Rayleigh's wave $c_{R}$. Since this velocity is used to calculate the shear modulus $G$ of an investigated half-space according to the formula:

$G=\rho \cdot\left(c_{R} / r_{v}\right)^{2}$,

where:

$\rho$ - the bulk density of investigated half-space,

$r_{v}$ - velocity ratio of Rayleigh's and shear wave [3],

the calculated shear modulus will also be different. There are the calculated shear modulus values in Table 2. As it is stated in [4], the value of the bulk density can vary depending on the velocity of Rayleigh's wave and the type of used FWD. To minimize the possible influence of the bulk density, only one value $\left(1.820 \mathrm{~g}^{\mathrm{cm}} \mathrm{cm}^{-3}\right)$ was used in the calculations. It is approximately the middle value of the range according to [4] for the Dynatest FWD. The distance values in Table 2 correspond to the distance between the receiver in centreline of a load and the others receivers.

Table 2: The shear modulus determined according to two procedures.

\begin{tabular}{|c|c|c|c|c|c|c|c|}
\hline \multirow{2}{*}{$\begin{array}{c}\text { Distance of } \\
\text { the receivers } \\
\text { [mm] }\end{array}$} & \multicolumn{2}{|c|}{ Travel time [m·s] } & \multicolumn{2}{c|}{ Velocity [m.s ${ }^{-1}$ ] } & \multicolumn{3}{c|}{ Shear modulus [MPa] } \\
\cline { 2 - 8 } & Formula (2) & $\begin{array}{c}\text { Deflection } \\
\text { curve }\end{array}$ & Formula (2) & $\begin{array}{c}\text { Deflection } \\
\text { curve }\end{array}$ & Formula (2) & $\begin{array}{c}\text { Deflection } \\
\text { curve }\end{array}$ & Difference [\%] \\
\hline 200 & 0.30 & 0.33 & 666.67 & 606.06 & 8651.2 & 7149.8 & 21.0 \\
\hline 300 & 0.55 & 0.59 & 545.45 & 508.47 & 5791.3 & 5032.7 & 15.1 \\
\hline 450 & 0.93 & 1.00 & 486.49 & 450.00 & 4606.8 & 3941.7 & 16.9 \\
\hline 600 & 1.45 & 1.52 & 413.79 & 394.74 & 3332.9 & 3033.0 & 9.9 \\
\hline 900 & 2.70 & 2.92 & 333.33 & 308.22 & 2162.8 & 1849.2 & 17.0 \\
\hline 1200 & 4.40 & 4.50 & 272.73 & 266.67 & 1447.8 & 1384.2 & 4.6 \\
\hline 1500 & 6.43 & 6.54 & 233.46 & 229.36 & 1061.0 & 1024.0 & 3.6 \\
\hline 1800 & 8.45 & 8.61 & 213.02 & 209.06 & 883.3 & 850.7 & 3.8 \\
\hline
\end{tabular}

As it was expected, the shear modulus determined according to two mentioned procedures are different. In this case, all modulus determined from the time of a wave occurrence at receivers derived using the course of the deflection curve are lower. The difference is not equal, but changes with the distance between the receivers. The highest difference in nominal values and also in percentage was identified when shorter distance of the receivers was used in the calculations. This issue was discussed in [5]. The relevant question is how it is important from bearing capacity evaluation point of view. To answer it the criteria of bearing capacity evaluation according to [6] were consulted.

However, there is the value of elastic modulus used as the classification criterion, not the shear modulus value. The relation between the shear modulus and elastic modulus in tension-compression is according to [7] done via formula:

$E=2 G \cdot(1+v)$, 
where $v=$ Poisson`s ratio.

It means the differences in the shear modulus remain the same and the classification values in [2] can be used to assess whether the differences of the shear modulus are significant or not. The range of modulus in one classification class varies from $50 \mathrm{MPa}$ to $100 \mathrm{MPa}$ (depending on the category of traffic intensity). From this point of view the differences in the shear modulus determined according to presented two methods could be very significant if the values calculated for short distance of the receiver are used. In the case of longer distance of the receivers the differences are not so high and significant.

\section{Conclusions}

The FWD time history data was assessed with regard to possible using in the method of the Spectral Analysis of Surface Waves. Basically, the possibility to determine the velocity of a generated surface wave was evaluated. It was found out the same deflection values exist at consecutive time intervals in the relevant part of the time history data (the arrival of the front of the wave or the area of maximum deflection value). Two methods were used to determine the exact time of the wave occurrence at receivers. It was concluded the differences between the used methods exist. It means the calculated velocities of a wave and shear modulus are also different.

Importance of the shear modulus differences was estimated using the Slovak bearing capacity classification based on elastic modulus values. Taking into account the range of modulus in one classification class it can be stated the importance of the differences depends on the distance between the used receivers. When the distance is short, differences are high and significant and vice versa.

\section{Acknowledgement}

The author is grateful for the financial support from the research project VEGA 1/005/16 Modelling of selected dynamic problems in time and frequency domain.

\section{References}

[1] MADSHUS, C. - WESTERDAHL, H.: Surface wave measurements for construction control and maintenance planning of roads and airfields. $3^{\text {rd }}$ International Conference on Bearing Capacity of Roads and Airfields, 3 - 5 July 1990, Trondheim.

[2] ALEXANDER, D. R.: In situ material characterization for pavement evaluation using surface wave techniques. $3^{\text {rd }}$ International Conference on Bearing Capacity of Roads and Airfields, 3 - 5 July 1990, Trondheim.

[3] KOŠOVÁ, M.: Dynamic diagnostics of pavement layers stiffness on new-built motorway sections (in Slovak). Diploma thesis. University of Zilina, 1998.

[4] KOMAČKA, J. - RAPANOVÁ, N.: Interpretation of results of asphalt pavement bearing capacity diagnostics by FWD based on the theory of waves propagation in half-space (in Slovak). Silniční obzor, Vol. 73, Iss. 7-8, 2012, pp. 205-209.

[5] KOMAČKA, J.: Experience with the application of the spectral analysis of surface waves method on a falling weight deflectometer time history. MATEC web of conferences: Dynamics of civil engineering and transport structures and wind engineering - DYN-WIND'2017, Vol. 107, 2017, article num. 00027.

[6] TP 1/2009 Measuring and evaluation of bearing capacity of asphalt pavements by FWD KUAB. Technical requirements (in Slovak). MDPaT SR, 2008. Available at: http://www.ssc.sk/files/docu ments/technicke-predpisy/tp2009/tp-01_2009.pdf.

[7] KUCHÁROVÁ, D. - MELCER, J.: Dynamic of structures (in Slovak). University of Žilina, 2000. 